\title{
Natural Orifice Transluminal Endoscopic Surgery (NOTES): an Emerging Technique in Surgery
}

\author{
Shrestha BM \\ Sheffield Kidney Institute, Sheffield, United Kingdom
}

\begin{abstract}
Natural orifice transluminal endoscopic surgery (NOTES), which utilises natural anatomical passages for gaining access to the intra-abdominal organs for surgical interventions, that result in scarless surgery, is a recent advancement in the specialty of minimally invasive surgery and has gained significant momentum, It has been postulated as a promising alternative to laparoscopic surgery in the field of minimal invasive surgery. Significant advantages over conventional open surgery, such as less postoperative pain, a shorter hospital stay, early return to activity, avoidance of woundrelated complications and better cosmesis have been demonstrated. This article provides an update in the development, principles, practice and future applications of NOTES.
\end{abstract}

Keywords: natural orifice, minimally invasive, scarless, endoscopic surgery

\section{INTRODUCTION}

Minimally-invasive surgery has gained significant popularity because of its advantages over traditional open surgical techniques, such as less post-operative pain, less analgesics requirements, a short hospital stay, early return to work, fewer complications and better cosmesis. Over the past three decades, surgery has advanced from open to minimally-invasive surgery in the form of conventional laparoscopic and more lately, to the natural orifice transluminal endoscopic surgery (NOTES) and robotic-assisted surgery. ${ }^{1}$
Conventional minimally-invasive techniques involve accessing organs through naturally existing body cavities or anatomical planes, percutaneously, for visualisation and instrumentation, thereby leaving behind a few external scars permanently. NOTES is a new surgical concept, which involves accessing the abdominal cavity through naturally existing passages such as the stomach, rectum, vagina and bladder without actually puncturing or incising the abdominal wall and thus resulting in scarless surgery. NOTES has been examined both in experimental and clinical settings and has shown to offer advantages over conventional surgical techniques. ${ }^{2}$

Correspondence:

B M Shrestha

Sheffield Kidney Institute, Sheffield, S5 7AU, UK

E-mail: shresthabm@doctors.net.uk 
Natural orifice transluminal endoscopic surgery is shown to have many advantages over the conventional laparoscopic surgery, such as improved cosmetic appearance, less postoperative pain, reduction in the MRSA infection, reduced incidence of wound site hernias and reduction in the psychological impact of the trauma and discomfort of surgery. ${ }^{3}$ As a consequence, this leads to faster return to normal activity and enhances the quality of life. NOTES has opened a highly interesting field for certain types of patients, such as those with high surgical risks, the morbidly obese, and those with multiple prior abdominal interventions or surgical wound infections. ${ }^{4}$ This article provides an update in the development, principles, current practice and future applications of NOTES.

\section{MILESTONES OF NOTES}

Natural orifice transluminal endoscopic surgery has been tried in animal models by performing a wide variety of procedures such as cholecystectomy, appendicectomy, splenectomy, hysterectomy, tubal ligations, gastroenteric anastomosis, peritoneoscopy, liver biopsy and herniorrhaphy. ${ }^{5}$ In a pig model, Kalloo performed the first transgastric peritoneoscopy and liver biopsies in 2002, with no morbidity and mortality, thereby introducing the concept of NOTES. ${ }^{6}$ This was soon followed by transgastric appendicectomy by Rao, who demonstrated his video at the American College of Surgeons in 2005. The first transgastric cholecystectomy was performed by Per-Ola Park in 2003 in Sweden and reported in 2005. ${ }^{7}$ Zorron et al. reported the first human case of transvaginal retroperitoneoscopy and successful excision of a lower polar renal cyst. ${ }^{8}$ Recently, transgastric repair of an abdominal wall hernia has been described in an animal model. ${ }^{9}$ Although NOTES is still in the stage of its infancy, this technique is being examined in various subspecialties and successful outcomes have been reported in the recent past. ${ }^{10}$

\section{PRINCIPLES OF NOTES}

Access to the intra-abdominal organs is gained through natural orifices such as the mouth and vagina, although there are reports of access through the rectum and urinary bladder. ${ }^{11-14}$ The stomach or vagina is punctured and carbon dioxide is insufflated through the endoscope. The pneumoperitoneum created is maintained, thus developing a working space for the performance of intra-abdominal procedures. ${ }^{15}$ Innovation of surgical instruments and endoscopes up to a diameter of 2 $\mathrm{mm}$, both rigid and flexible, capable of producing high resolution images is a major advancement which has made NOTES possible.

\section{TRANSGASTRIC ACCESS}

Transgastric access involves introduction of an endoscope into the stomach, followed either by performing a small gastrotomy, which is then balloondilated, or by fashioning a large gastrotomy using a cutting diathermy. The endoscope is advanced through the stomach wall into the abdominal cavity. After completion of the procedures, the gastrotomy is closed with clips.

\section{TRANSVAGINAL ACCESS}

Direct access to the peritoneal cavity is gained through the transvaginal route by performing a posterior colpotomy. A valved trocar is introduced into the pelvis through the colpotomy to facilitate the creation of pneumoperitoneum and the introduction of instruments for performing NOTES. ${ }^{16}$

\section{TRANSVESICAL ACCESSES}

Access to the intra-abdominal organs through the urinary bladder has been obtained and successful cholecystectomies have been performed in pigs using a combined transgastric and transvesical approach. ${ }^{17}$

\section{TRANSRECTAL ACCESS}

The combination of transgastric flexible endoscopy to facilitate transrectal colonic mobilisation has been successful in porcine models. In human clinical settings, the combined transanal and laparoscopic sigmoid mobilisation for NOTES transrectal total mesorectal excision and lymphadenectomy has been successfully performed. ${ }^{18}$

\section{COMPLICATIONS OF NOTES}

The complications related to NOTES are similar to those encountered in any laparoscopic surgery, that is, injury to intra-abdominal viscera and side-effects of pneumoperitoneum on visceral functions. An additional risk of contamination of the peritoneal cavity from the access sites such as the stomach, vagina, bladder or rectum exists which is overcome through meticulous surgery and antibiotics prophylaxis. Currently, transvaginal access of NOTES has been found to be of minimal risk in human beings. However, dyspareunia, vaginal cuff haematoma and infection from prolonged surgery have been observed. ${ }^{16}$

\section{CURRENT STATUS OF NOTES}

Most of the NOTES have been carried out in the American centres. However, several other centres have gained significant experience on NOTES and have published satisfactory outcomes with high safety profiles. 
Cholecystectomy has been performed successfully through both transgastric ${ }^{19}$ and transvaginal routes $^{20}$ where organs were delivered through the mouth and vagina, respectively. In a recent publication from the German NOTES registry showing results of 551 transvaginal cholecystectomy, conversion to open cholecystectomy was required in $4.9 \%$ and complications occurred in $3.1 \%$ of all patients. ${ }^{21}$ In another report, transvaginal appendicectomy was performed successfully in 33 patients with no postoperative complications. ${ }^{22}$ Lately, Gill et al. successfully performed live donor nephrectomy in 4 cases for renal transplantation purpose by using NOTES technique, where they introduced a single port through the umbilicus and delivered the kidney through the same route with no visible scar, and named the procedure as embryonic-NOTES (E-NOTES). ${ }^{23}$

It is anticipated that the advantages of NOTES will enhance its scope, particularly for critically ill patients in intensive care units. Transgastric peritoneoscopy for acute mesenteric ischaemia, assessment of the length of an ischaemic small bowel to make a decision for a laparotomy and in abdominal trauma patients to assess the degree of intra-abdominal injury is expected to be carried out Under sedation rather than general anaesthesia without transferring patients across to the operating theatres. ${ }^{24}$ It is expected that, as this field develops, other specialties such as urology, obstetrics and gynecology, and cardiothoracic surgery may find the natural orifice to be a kinder and gentler point of entry.

Although some indications for NOTES procedures in surgical oncology have been identified, these techniques have to be assessed cautiously. Implementation of NOTES in surgical oncology is currently difficult because of technical problems, lack of intraoperative orientation and abdominal adhesions. ${ }^{25}$
There is no report of NOTES from the United Kingdom. The Association of Laparoscopic Surgeons of Great Britain and Ireland has published a declaration on its website warning their members and patients as NOTES should still be considered as an experimental surgery. Every innovative procedure in surgery has been subjected to scrutiny in its introductory phase, but eventually it has crossed the hurdle of the learning curve with the passage of time, and, therefore, NOTES should not be an exception. This is expected to be a routine practice in the forthcoming decades all over the world. ${ }^{26}$

\section{TRAINING IN NOTES}

A research-oriented, multidisciplinary team comprising of general, gynaecological and urological surgeons, gastroenterologists and endoscopists is needed to consolidate the diverse skill set that is needed to develop expertise in NOTES. A training programme where facilities are available for learning NOTES using simulators, animals and human cadaveric models before moving on to human trials is essential. NOTES requires high-quality equipment for optimum performance, which, in addition, are expensive. Therefore, the training and utility of NOTES should be limited to larger tertiary teaching hospitals where resources are adequate enough for the long-term sustenance of the programme.

\section{CONCLUSIONS}

Natural orifice transluminal endoscopic surgery is a new and novel concept in surgical practice. The preliminary results of NOTES in various specialties appear promising. Despite the proposed potential benefits of NOTES, their safety and efficacy are yet to be evaluated in large randomised trials in each specialty, particularly in oncology, where oncological and functional outcomes are paramount. Further research in animal and human cadaveric models is requisite prior to human application, especially for complex surgeries.

\section{REFERENCES}

1. Yan SL, Thompson-Fawcett M. NOTES: new dimension of minimally invasive surgery. ANZ J Surg 2009;79(5):337-43.

2. Giday SA, Kantsevoy SV, Kalloo AN. Principle and history of Natural Orifice Translumenal Endoscopic Surgery (NOTES). Minim Invasive Ther Allied Technol 2006;15(6):373-7.

3. Shafi BM, Mery CM, Binyamin G, Dutta S. Natural orifice translumenal endoscopic surgery (NOTES). Semin Pediatr Surg 2006;15(4):251-8.

4. Jay Pasricha P, Krummel TM. NOTES and other emerging trends in gastrointestinal endoscopy and surgery: the change that we need and the change that is real. Am J Gastroenterol 2009;104(10):2384-6.

5. Wagh MS, Thompson CC. Surgery insight: natural orifice transluminal endoscopic surgery--an analysis of work to date. Nat Clin Pract Gastroenterol Hepatol 2007;4(7):386-92.

6. Kalloo AN, Singh VK, Jagannath SB, Niiyama H, Hill SL, Vaughn $\mathrm{CA}$, et al. Flexible transgastric peritoneoscopy: a novel approach to diagnostic and therapeutic interventions in the peritoneal cavity. Gastrointest Endosc 2004;60(1):1147 . 
7. Park PO, Bergstrom M, Ikeda K, Fritscher-Ravens A, Swain P. Experimental studies of transgastric gallbladder surgery: cholecystectomy and cholecystogastric anastomosis (videos). Gastrointest Endosc 2005;61(4):601-6.

8. Zorron R, Goncalves L, Leal D, Kanaan E, Cabral I, Saraiva P. Transvaginal hybrid natural orifice transluminal endoscopic surgery retroperitoneoscopy--the first human case report. J Endourol 2010;24(2):233-7.

9. $\quad$ Earle DB, Desilets DJ, Romanelli JR. NOTES((R)) transgastric abdominal wall hernia repair in a porcine model. Hernia 2010;July 10 (Epub ahead of publication).

10. Bergman S, Melvin WS. Natural orifice translumenal endoscopic surgery. Surg Clin North Am 2008;88(5):1131-48, viii.

11. Hazey JW, Narula VK, Renton DB, Reavis KM, Paul CM, Hinshaw KE, et al. Natural-orifice transgastric endoscopic peritoneoscopy in humans: Initial clinical trial. Surg Endosc 2008;22(1):16-20.

12. Gettman MT, Blute ML. Transvesical peritoneoscopy: initial clinical evaluation of the bladder as a portal for natural orifice translumenal endoscopic surgery. Mayo Clin Proc 2007;82(7):843-5.

13. Zorron R, Filgueiras M, Maggioni LC, Pombo L, Lopes Carvalho G, Lacerda Oliveira A. NOTES.Transvaginal cholecystectomy: report of the first case. Surg Innov 2007;14(4):279-83.

14. Sylla P, Willingham FF, Sohn DK, Gee D, Brugge WR, Rattner DW. NOTES rectosigmoid resection using transanal endoscopic microsurgery (TEM) with transgastric endoscopic assistance: a pilot study in swine. J Gastrointest Surg 2008;12(10):1717-23.

15. Hondo FY, Giordano-Nappi JH, Maluf-Filho F, Matuguma SE, Sakai P, Poggetti R, et al. Transgastric access by balloon overtube for intraperitoneal surgery. Surg Endosc 2007;21(10):1867-9.

16. Branco AW, Branco Filho AJ, Kondo W, Noda RW, Kawahara N, Camargo AA, et al. Hybrid transvaginal nephrectomy. Eur Urol 2008;53(6):1290-4.
17. Rolanda C, Lima E, Pego JM, Henriques-Coelho T, Silva D, Moreira I, et al. Third-generation cholecystectomy by natural orifices: transgastric and transvesical combined approach (with video). Gastrointest Endosc 2007;65(1):111-7.

18. Zorron R, Phillips HN, Coelho D, Flach L, Lemos FB, Vassallo RC. Perirectal NOTES Access: "Down-to-Up" Total Mesorectal Excision for Rectal Cancer. Surg Innov 2012;19(1):11-9.

19. Auyang ED, Hungness ES, Vaziri K, Martin JA, Soper NJ Human NOTES cholecystectomy: transgastric hybrid technique. J Gastrointest Surg 2009;13(6):1149-50.

20. Ramos AC, Murakami A, Galvao Neto M, Galvao MS, Silva AC, Canseco EG, et al. NOTES transvaginal video-assisted cholecystectomy: first series. Endoscopy 2008;40(7):572-5.

21. Lehmann KS, Ritz JP, Wibmer A, Gellert K, Zornig C, Burghardt J, et al. The German registry for natural orifice translumenal endoscopic surgery: report of the first 551 patients. Ann Surg 2010;252(2):263-70.

22. Nezhat C, Datta MS, Defazio A, Nezhat F, Nezhat C. Natural orifice-assisted laparoscopic appendectomy. Jsls 2009;13(1):14-8.

23. Gill IS, Canes D, Aron M, Haber GP, Goldfarb DA, Flechner $\mathrm{S}$, et al. Single port transumbilical (E-NOTES) donor nephrectomy. J Urol 2008;180(2):637-41; discussion 41.

24. Trunzo JA, Poulose BK, McGee MF, Nikfarjam M, Schomisch SJ, Onders RP, et al. The diagnostic efficacy of natural orifice transluminal endoscopic surgery: is there a role in the intensive care unit? Surg Endosc 2010 March (Epub ahead of publication).

25. Chopra SS, Mrak K, Warnick P, Huenerbein M. Natural orifice transluminal endoscopic surgery in surgical oncology: analysis of indications and feasibility in cancer patients. Hepatogastroenterology. 2012;59(116):1131-4.

26. Surlin V, Saftoiu A, Rimbas M, Vilmann P. Notes--"state of the art" surgical gastroenterology: the beginning of the voyage. Hepatogastroenterology 2010;57(97):54-61. 